\title{
Regular Physical Activity during Pregnancy Improves Maternal Depressive Symptoms
}

\author{
Ibrahim Ahmad Abubakar \\ Department of Physiotherapy, Abubakar Tafawa Balewa Teaching Hospital, Bauchi state, NIGERIA.
}

\section{Dear Editor,}

Depressive symptoms, such as extended feeling of sadness, decreased selfesteem, suicidal propensities, unconcern in activities, feelings of hopelessness and helplessness, low energy, difficulty in making decisions, sleep disorders, anxiety, petulance, and changes in eating patterns are related with an increased risk of health conditions such as osteoporosis, cardiovascular diseases, and dementia. ${ }^{[1]}$ Women of childbearing age of about $22 \%$ have been estimated to have experienced depression at some point in their lives and pregnancy is a vulnerable time for depression compared with other periods of life. ${ }^{[2]}$

Depression is found to be higher during pregnancy than that in the postpartum period of childbearing women which was shown to be $10 \%-30 \%$ prevalent in several studies. ${ }^{[3]}$ Progesterone and oestrogens are found to be in large quantity during pregnancy period and are likely the cause of depression during pregnancy, it influences the neural structures that are known to be important in regulating mood by raising the sensitivity to changes in levels of b-endorphins and dopamine. ${ }^{[4]}$

Depressive symptoms that occur during pregnancy period have a negative impact on the child which include behavioural problems at the early few months of life, impaired development of child's cerebrum, risk of preterm deliveries, difficulties in mother-infant bonding, difficulties in feeding by infants and problems with childhood overweight, decreased birth weight, and lengthier hospital stays. ${ }^{[5]}$

Probable antidepressants side effects on mother and the foetus as a result of pharmacological treatment at the time of pregnancy is not suggestive ${ }^{[[]}$ therefore, Former studies have supported the antidepressant effects of exercise in the general population including pregnant women ${ }^{[7]}$ and scientific evidence has proved that exercise at the time pregnancy does not lead to adverse effects on mother and her foetus, though significant improvements on psychological factors was seen. ${ }^{[8]}$

In a recent randomised control trial, a well controlled 3 months aerobic exercise improves depressive symptoms during pregnancy period. ${ }^{[9]}$ Pregnant women on their own have acknowledged that exercise is a paramount aspect of postnatal well-being but despite the beneficial effect of Physical activity in the improvement of health, pregnant women have stated difficulties continuing with exercise in the postnatal period. ${ }^{[10]}$

In conclusion, engagement in Physical activity at the time of pregnancy does not lead to any adverse effects on mother and her foetus during pregnancy but improves maternal depressive symptoms. Pregnant women are encouraged to participate in at least three months supervised and prescribed moderate aerobic exercises.

\section{REFERENCES}

1. Melville JL, Gavin A, Guo Y, et al. Depressive disorders during pregnancy: Prevalence and risk factors in a large urban sample. Obstetrics and Gynecology. 2010;116(5):1064-70.

2. Campagne DM. The obstetrician and depression during pregnancy. European Journal of Obstetrics and Gynecology and Reproductive Biology. 2004;116(2):12530.

3. Lee AM, Lam SK, Lau SM, et al. Prevalence, course, and risk factors for antenatal anxiety and depression. Obstetrics and Gynecology. 2007;110(5):1102-12.

4. Poudevigne M, O'Connor P. A review of physical activity physical activity patterns in pregnant women and their relationship to psychological health. Sports Medicine. 2006;36(1):19-38.

5. Field T. Prenatal depression effects on early development: A review. Infant Behaviour and Development. 2011;34(1):1-14.

6. Hammond S, Crozier K. Depression: Assessing the causes: In their second paper, midwife at the Queen Elizabeth Hospital, Kings Lynn Sarah Hammond and lecturer in midwifery at the University of East Anglia Kenda Crozier examine the need for early assessment of perinatal depression and possible ways of avoidance. Midwives Magazine. 2007;10(8):365-8.

7. Martinsen EW. Physical activity in the prevention and treatment of anxiety and depression. Nordic Journal of Psychiatry. 2008;62(sup47):25-9.

8. Barakat R, Pelaez M, Montejo R, Luaces M, Zakynthinaky M. Exercise during pregnancy improves maternal health perception: A randomized controlled trial. American Journal of Obstetrics and Gynecology. 2011;204(5):402-e1-7.

9. Roblebo AF, Sandoval N, Mosguero YF, Escobar C, Ramirez R. Aerobic training during pregnancy reduces depressive symptoms in nulliparous women: $\mathrm{A}$ randomised trial. J Physiother. 2012;58(1):9-15.

10. Lox $\mathrm{CL}$, Treasure $\mathrm{DC}$. Changes in feeling states following aquatic exercise during pregnancy. J Applied Social Psychol. 2000;30(3):518-27.

Received: 26 Jan 2021; Accepted: 28 Mar 2021

Correspondence:

PT. Ibrahim Ahmad Abubakar (BPT)

Department of Physiotherapy, Abubakar Tafawa Balewa Teaching Hospital, Bauchi state, NIGERIA.

Email: ibrahimcsskd@gmail.com

Cite this article as: Abubakar IA. Regular Physical Activity during Pregnancy Improves Maternal Depressive Symptoms. J Pharm Pract Community Med. 2021;7(1):17. 